\title{
Phylogenetic positions of phytoplasmas associated with dieback, yellow crinkle and mosaic diseases of papaya, and their proposed inclusion in ' Candidatus Phytoplasma australiense' and a new taxon, 'Candidatus Phytoplasma australasia'
}

\author{
Daniel T. White, ${ }^{1}$ Linda L. Blackall, ${ }^{2}$ Paul T. Scott ${ }^{1}$ and Kerry B. Walsh ${ }^{1}$
}

Author for correspondence: Daniel T. White. Tel: +6174930 6324. Fax: +61749306536. e-mail: whited@topaz.cqu.edu.au

\footnotetext{
1 Plant Sciences Group, Primary Industries Research Centre, School of Biological and Environmental Sciences, Central Queensland University, Rockhampton Qld 4702, Australia

2 Centre for Bacterial Diversity and Identification, Department of Microbiology, University of Queensland, Brisbane Qld 4072, Australia
}

DNA extracted from three papaya (Carica papaya L.) plants, individually affected by dieback, yellow crinkle or mosaic diseases, was subjected to PCR using phytoplasma-specific primers to amplify the 16S rRNA gene plus 16S-235 rRNA intergenic spacer region. Near-complete DNA sequences obtained for the three PCR amplimers were subjected to phylogenetic analyses and direct sequence comparison with other phytoplasma 16S rDNA and 16S-23S spacer region DNA sequences. The papaya yellow crinkle (PpYC) and papaya mosaic (PpM) sequences were identical to each other, but distinctly different from the papaya dieback (PpDB) sequence, showing 90.3\% identity in the 16S rDNA and 87.8\% identity in the 165-23S spacer region DNA sequences. A phylogenetic tree based on 165 rDNA sequences was calculated, in which PpYC and PpM are most closely related to the tomato big bud phytoplasma (TBB; 99.7\% 16S rDNA sequence identity) from Australia, within subclade iit. This subclade consists of strains only reported occurring in the Southern Asian region and Australia, which indicates an Asian/Australasian origin. PpDB is most closely related to the Phormium yellow leaf phytoplasma from New Zealand (PYL; 99.9\% identity) and the Australian grapevine yellows phytoplasma (AGY; 99.7\% identity). These three phytoplasma strains form a distinct clade within subclade xii, which also includes the European strains STOL and VK as another distinct clade. The origin of the closely related but geographically separated AGY-like strains and STOL-like strains of subclade Xii is unclear. It is proposed that phytoplasma strains PpDB, PYL and AGY be included in the previously described taxon 'Candidatus Phytoplasma australiense', and that PpYC, PpM and TBB be assigned to a new taxon, 'Candidatus Phytoplasma australasia'.

Keywords: phytoplasmas, phylogeny, papaya, 16S rDNA, classification

\section{INTRODUCTION}

Dieback, yellow crinkle and mosaic are three important diseases of papaya (Carica papaya L.) in Australia. Dieback, the most severe of these diseases, is responsible for annual plant losses of $10 \%$, and up to $100 \%$ during epiphytotics, in central and Southern

The EMBL accession numbers for the sequences reported in this paper are Y10095 (PpDB), Y10097 (PpYC) and Y10096 (PpM).
Queensland plantations (Glennie \& Chapman, 1976). Yellow crinkle incidence is usually low and sporadic; however, epiphytotics can also occur. Papaya mosaic is generally of minor importance (Peterson et al., 1993; Simmonds, 1965). Incidences of dieback, yellow crinkle and possibly mosaic have recently been recorded in the Northern Territory (Condé et al., 1996). Transmission studies have demonstrated that the aetiologic agent of yellow crinkle is the same as that causing tomato big bud in Australia (Greber, 1966). Viruses were first thought to be the pathogens causing 
tomato big bud and papaya yellow crinkle; however, it was later shown by transmission electron microscopy that phytoplasmas are associated with both diseases (Bowyer et al., 1969; Gowanlock et al., 1976). Based on results of PCR detection, phytoplasmas have also been implicated as the aetiologic agents of papaya dieback and papaya mosaic (Davis et al., 1996; Gibb et al., 1996; Liu et al., 1996).

Phytoplasmas are cell-wall-less bacteria belonging to the class Mollicutes and are the proposed causative agents of diseases in several hundred plant species (McCoy et al., 1989). Phytoplasmas reside in the phloem tissue of the infected plant host and are transmitted by insect vectors, principally leafhoppers and planthoppers (Lee \& Davis, 1992). Although phytoplasmas have been detected in affected plant tissues and insects with the use of technologies based on the transmission electron microscope, antibodies and nucleic acids (Lee \& Davis, 1992), they are currently unable to be cultured in vitro. The association of phytoplasmas with dieback and mosaic in papaya has been based solely on PCR amplification of the $16 \mathrm{~S}$ rRNA gene and adjacent regions using phytoplasmaspecific primers (Davis et al., 1996; Gibb et al., 1996; Liu et al., 1996). The phytoplasmal origin of PCR amplimers from dieback-, mosaic- and yellow-crinkleaffected papaya has been confirmed by restriction endonuclease and DNA sequence analyses (Gibb et al., 1996; White et al., 1997).

Due to the inability to culture phytoplasmas in vitro, taxonomy based on phenotypic characteristics has not been possible. To date, the most reliable classifications of phytoplasmas have been based on DNA restriction analysis and phylogenetic sequence analysis, usually of the PCR-amplified 16S rRNA gene plus 16S-23S rRNA intergenic spacer region (R. E. Davis et al., 1997; R. I. Davis et al., 1997; Gundersen et al., 1994, 1996; Lee et al., 1993; Namba et al., 1993; Schneider et al., 1993, 1995a, b; Seemüller et al., 1994). These analyses have allowed the provisional classification of phytoplasmas from Europe, North America, Asia and Australia. The phytoplasmas are phylogenetically distinct from the other members of the class Mollicutes, forming a monophyletic clade with the closest relatives belonging to the genus Acholeplasma (Gundersen et al., 1994; Kuske \& Kirkpatrick, 1992; Namba et al., 1993; Seemüller et al., 1994). Among the phytoplasmas, Seemüller et al. (1994) identified five phylogenetic strain clusters, some of which could be divided into sub-groups. Schneider et al. (1995a) later distinguished a sixth strain cluster. In an alternative classification, Gundersen et al. (1994) identified 11 subclades within five strain clusters. Two further subclades were proposed by R. E. Davis et al. (1997) and Liefting et al. (1996) within the classification of Gundersen et al. (1994). The classification systems of Seemüller et al. (1994) and Gundersen et al. (1994) are both commonly referred to, and can be directly compared with each other due to the inclusion of representative strains common to both systems.
The phytoplasmas associated with papaya dieback, yellow crinkle and mosaic have been grouped according to RFLP analysis of PCR-amplified $16 \mathrm{~S}$ rDNA plus 16S-23S spacer region DNA (Gibb et al., 1996). In this paper, we report on the analysis of the DNA sequences of the 16S rRNA gene and 16S-23S spacer region of the phytoplasmas associated with Australian papaya dieback (PpDB), yellow crinkle (PpYC) and mosaic (PpM), and the positions of these strains in the current 16S rDNA phylogenetic classification systems.

A preliminary summary of this work has previously been presented at the Australasian Plant Pathology Society 11th Biennial Conference, Perth, Western Australia, 1997.

\section{METHODS}

Extraction of phytoplasma DNA. Papaya plants exhibiting characteristic symptoms of dieback, yellow crinkle or mosaic (Glennie \& Chapman, 1976; Peterson et al., 1993; Simmonds, 1965) were collected from a commercial plantation at Yarwun, central Queensland, during January and February 1995. Nucleic acids were extracted from the midribs of fresh, symptomatic leaves as previously described by Liu et al. (1996). The dried DNA pellets were resuspended in $50 \mu \mathrm{l}$ sterile, Millipore-filtered, distilled water and stored at $-20^{\circ} \mathrm{C}$. One extract was prepared from each of a dieback-, yellow-crinkle- and mosaic-affected papaya plant.

PCR amplification. Phytoplasma-specific PCR primers P1 and $\mathrm{P7}$ (Table 1) were used to amplify a region approximately $1800 \mathrm{bp}$ in length, consisting of the $16 \mathrm{~S}$ rRNA gene, the $16 \mathrm{~S}-23 \mathrm{~S}$ rRNA intergenic spacer region and approximately $50 \mathrm{bp}$ of the $5^{\prime}$ end of the $23 \mathrm{~S}$ rRNA gene. Total PCR volumes were $100 \mu 1$ and contained $200 \mu \mathrm{M}$ of each dNTP, $0.4 \mu \mathrm{M}$ of each primer, $1 \times$ DNA polymerase reaction buffer, $1 \mathrm{U}$ Taq DNA polymerase (Boehringer) and $5 \mu \mathrm{l}$ template DNA solution. Each reaction mixture was covered with $50 \mu \mathrm{l}$ sterile mineral oil (Sigma). Reactions were performed in a Minicycler (M. J. Research) with initial denaturation at $94^{\circ} \mathrm{C}$ for $2 \mathrm{~min}$, followed by 40 cycles consisting of denaturation at $94{ }^{\circ} \mathrm{C}$ for $1 \mathrm{~min}$, annealing at $52^{\circ} \mathrm{C}$ for $30 \mathrm{~s}$ and extension at $72^{\circ} \mathrm{C}$ for $30 \mathrm{~s}$, with extension in the final cycle for $2 \mathrm{~min}$. Five microlitres of each PCR product was subjected to electrophoresis in a $1.0 \%(\mathrm{w} / \mathrm{v})$ agarose gel, stained with ethidium bromide and observed under UV illumination. A total of four PCRs was performed for each DNA extract and the amplification products were pooled for each disease.

DNA sequencing. The amplification products were purified for sequencing using the Promega Wizard PCR Preps spin column purification system, according to the manufacturer's instructions for PCR product purification without a vacuum manifold. For each of the DNA extracts, the pooled PCR amplimers were eluted from the mini columns with $100 \mu \mathrm{l}$ sterile, Millipore-filtered, distilled water.

Overlapping regions of both strands of the amplimers were sequenced using 13 primers typically used for sequencing bacterial 16S rRNA genes (Table 1) (Blackall et al., 1994; Bradford et al., 1996). The forward primer P3 (Table 1) was used in conjunction with $\mathrm{P} 7$ to sequence the $16 \mathrm{~S}-23 \mathrm{~S}$ rRNA spacer region. Direct cycle sequencing reactions were performed using the PRISM Ready Reaction DyeDeoxy Terminator Sequencing kit (Applied Biosystems). Three to 
Table 1. PCR amplification and sequencing primers

\begin{tabular}{|lll|}
\hline Primer & \multicolumn{1}{c|}{${\left.\text { Nucleotide sequence* } \mathbf{( 5}^{\prime} \rightarrow \mathbf{3}^{\prime}\right)}$} & \multicolumn{1}{c|}{ Reference } \\
\hline P1 & AAGAGTTTGATCCTGGCTCAGGATT & Deng \& Hiruki (1991) \\
$27 \mathrm{f}$ & GAGTTTGATCCTGGCTCAG & Dorsch \& Stackebrandt (1992) \\
$342 \mathrm{r}$ & CTGCTGCSYCCCGTAG & Lane (1991) \\
$357 \mathrm{f}$ & CTCCTACGGGAGGAGCAG & Lane (1991) \\
$519 \mathrm{r}$ & GWATTACCGCGGCKGCTG & Lane (1991) \\
$530 \mathrm{f}$ & GTGCCAGCMGCCGCGG & Lane (1991) \\
$787 \mathrm{r}$ & CTACCAGGGTATCTAAT & Stackebrandt \& Charfreitag (1990) \\
$803 \mathrm{f}$ & ATTAGATACCCTGGTAG & Stackebrandt \& Charfreitag (1990) \\
$907 \mathrm{r}$ & CCGTCAATTCMTTTRAGTT & Lane (1991) \\
$926 \mathrm{f}$ & AAACTYAAAKGAATTGACGG & Lane (1991) \\
$1100 \mathrm{r}$ & GGGTTGCGCTCGTTG & Lane (1991) \\
$1114 \mathrm{f}$ & GCAACGAGCGCAACCC & Lane (1991) \\
$1392 \mathrm{r}$ & ACGGGCGGTGTGTRC & Lane (1991) \\
$1492 \mathrm{r}$ & TACGGYTACCTTGTTACGACTT & Lane (1991) \\
P3 & GGATGGATCACCTCCTT & Schneider et al. (1995b) \\
P7 & CGTCCTTCATCGGCTCTT & Schneider et al. (1995b) \\
\hline
\end{tabular}

${ }^{*} M=C: A, Y=C: T, K=G: T, R=A: G, S=G: C, W=A: T ;$ all $1: 1$.

five microlitres of purified PCR product was used as template for the sequencing reactions. Reactions were performed in a Perkin Elmer model 480 thermal cycler and the thermal cycling profile was initial denaturation at $96^{\circ} \mathrm{C}$ for $2 \mathrm{~min}$, followed by 25 cycles consisting of denaturation at $96^{\circ} \mathrm{C}$ for $30 \mathrm{~s}$, reannealing at $50^{\circ} \mathrm{C}$ for $15 \mathrm{~s}$ and extension at $60^{\circ} \mathrm{C}$ for $4 \mathrm{~min}$. Reaction products were purified by the chloroform method described in the manufacturer's instructions for the sequencing kit and were electrophoresed and detected using an Applied Biosystems model 373A automated DNA sequencer.

Comparative sequence analysis. Initial sequence alignment and editing were done using the computer program SeqEd (Applied Biosystems). The overlapping sequence fragments were manually aligned against the Escherichia coli $16 \mathrm{~S}$ rDNA sequences according to secondary structure (Lane, 1991), and were compiled to give the full 16S rDNA plus $16 \mathrm{~S}-23 \mathrm{~S}$ spacer region DNA sequence of the PCR amplimer from each of the three papaya disease DNA extracts.

Further analyses were conducted using programs available via the Australian National Genomic Information Service (ANGIS). The full 16S rDNA plus 16S-23S spacer region sequences were subjected to BLAST (Altschul et al., 1990) analyses to search for similar sequences in the nucleic acid databases. All phytoplasma 16S rDNA sequences available in the nucleic acid databases, with a length of at least 1300 nucleotides, were used in the phylogenetic analyses (Table 2). Acholeplasma palmae, a closely related non-phytoplasma mollicute (R. E. Davis et al., 1997; Gundersen et al., 1994), was used as the outgroup. The reference sequences were aligned with the PpDB, PpYC and PpM sequences using CLUSTAL W (Thompson et al., 1994) and the ae2 editor (Larsen et al., 1993).

Phylogenetic trees were calculated using distance (DNADIST) and maximum parsimony (DNAPARS) method programs in PHYLIP version 3.5 (Felsenstein, 1993). Nucleotide positions at which a gap occurred in any of the aligned sequences were excluded from the analysis. An evolutionary distance matrix was calculated using the Jukes and Cantor-parameter model in DNADIST, and trees were constructed using the neighbourjoining method (NEIGHBOR). To quantify relative support for branches inferred from genetic distance analyses and parsimony, 'bootstrap' resampling (100 resamplings) was employed. A significance level of $95 \%$ was adopted for testing hypotheses proposed a priori (Felsenstein, 1985).

Phylogenetic distance trees were calculated from two data sets of 16S rDNA sequences. One set included the Japanese phytoplasma strains OY, TWB and RYD (Table 2), to give a total of 52 phytoplasma strains in the analyses and the comparison of 1251 nucleotide positions. A second data set excluded the Japanese phytoplasmas, allowing the analysis of only 49 phytoplasma strains, but enabling the comparison of 1353 nucleotide positions. The phylogenetic tree generated from the second data set is presented in the results since it is based on more sequence information than the tree based on the first data set. Using the ae 2 editor, a similarity matrix was constructed by direct pairwise comparison of all phytoplasma $16 \mathrm{~S}$ rDNA sequences used for phylogenetic inferences. The PpDB, PpYC and PpM 16S-23S spacer region DNA sequences were aligned and compared with 22 other available phytoplasma spacer region sequences (Table 2) using ae2. A similarity matrix was constructed as for the $16 \mathrm{~S}$ rDNA sequences.

\section{RESULTS}

\section{DNA sequences}

Almost the entire P1/P7 PCR amplimer was sequenced for each of the PpDB (1761 bp), PpYC (1799 bp) and PpM (1797 bp) phytoplasmas. Near-complete 16S rDNA sequences were obtained, except for up to $12 \mathrm{bp}$ at the $5^{\prime}$ end of the 16S rRNA gene of all three amplimers. The $16 \mathrm{~S}-23 \mathrm{~S}$ spacer region DNA sequences were $208 \mathrm{bp}$ in length for PpDB and $222 \mathrm{bp}$ in length for PpYC and PpM. Thirty-two base pairs of the $5^{\prime}$ end of the 23S rRNA gene was determined for $\mathrm{PpDB}$ and $56 \mathrm{bp}$ was determined for PpYC and PpM. 
Table 2. Associated diseases and accession numbers of $16 \mathrm{~S}$ rDNA and 16S-23S spacer region DNA sequences of phytoplasma strains used in this study

\begin{tabular}{|c|c|c|c|c|}
\hline Strain* & Associated plant disease and origin & Sequence $\dagger$ & Accession no. & Reference \\
\hline PpDB & Papaya dieback; Queensland, Australia & $16 \mathrm{~S}, \mathrm{SR}$ & Y10095 & This paper \\
\hline AGY & Grapevine yellows; South Australia, Australia & $16 \mathrm{~S}, \mathrm{SR}$ & X95706 & Padovan et al. (1996) \\
\hline PYL & Phormium yellow leaf ( $r r n B$ operon); New Zealand & $16 \mathrm{~S}$ & U43570 & Liefting et al. (1996) \\
\hline PYL & Phormium yellow leaf; New Zealand & SR & U43571 & Liefting et al. (1996) \\
\hline STOL & Stolbur of pepper; Serbia & $16 \mathrm{~S}$ & $\mathrm{X} 76427$ & Seemüller et al. (1994) \\
\hline VK & Vergilbungskrankheit (grapevine yellows); Germany & $16 \mathrm{~S}$ & X76428 & Seemüller et al. (1994) \\
\hline AAY & American aster yellows; FL, USA & $16 \mathrm{~S}$ & $\mathrm{X} 68373$ & Schneider et al. (1993) \\
\hline SAY & Severe Western aster yellows; CA, USA & $16 \mathrm{~S}, \mathrm{SR}$ & M86340 & Kuske \& Kirkpatrick (1992) \\
\hline AY1 & Maryland aster yellows; MD, USA & $16 \mathrm{~S}$ & L33767 & Gundersen et al. (1994) \\
\hline OY & Onion yellows; Japan & $16 \mathrm{~S}$ & D12569 & Namba et al. (1993) \\
\hline $\mathrm{RpPh}$ & Winter oilseed rape phyllody; Czech Republic & $16 \mathrm{~S}, \mathrm{SR}$ & U89378 & $-\ddagger$ \\
\hline OAY & Oenothera (Michigan) aster yellows; MI, USA & $16 \mathrm{~S}$ & M30790 & Lim \& Sears (1989) \\
\hline OAY & Oenothera (Michigan) aster yellows; MI, USA & SR & - & Lim \& Sears (1989) \\
\hline BB & Tomato big bud; AR, USA & $16 \mathrm{~S}$ & L33760 & Gundersen et al. (1994) \\
\hline $\mathrm{CCPh}$ & Clover phyllody; Ontario, Canada & $16 \mathrm{~S}$ & L33762 & Gundersen et al. (1994) \\
\hline KV & Clover phyllody; Germany & $16 \mathrm{~S}$ & $\mathrm{X} 83870$ & $-\ddagger$ \\
\hline ACLR & Apricot chlorotic leaf roll; Spain & $16 \mathrm{~S}$ & X68338 & Schneider et al. (1993) \\
\hline PPER & European stone fruit yellows of peach; Germany & $16 \mathrm{~S}$ & $\mathrm{X} 68374$ & Schneider et al. (1993) \\
\hline ESF-PCH & European stone fruit yellows of peach; Germany & SR & U54988 & Smart et al. (1996) \\
\hline ESFY & European stone fruit yellows of apricot; Czech Republic & $16 \mathrm{~S}, \mathrm{SR}$ & Y11933 & $-\ddagger$ \\
\hline AT & Apple proliferation; Germany & $16 \mathrm{~S}$ & $\mathrm{X} 68375$ & Schneider et al. (1993) \\
\hline AT & Apple proliferation; Germany & SR & U54985 & Smart et al. (1996) \\
\hline PD & Pear decline; Germany & $16 \mathrm{~S}$ & X76425 & Seemüller et al. (1994) \\
\hline PD-308 & Pear decline; Germany & SR & U54989 & Smart et al. (1996) \\
\hline PYLR2 & Peach yellow leaf roll; CA, USA & SR & U54990 & Smart et al. (1996) \\
\hline APS & Apple proliferation; Spain & $16 \mathrm{~S}$ & X76426 & Seemüller et al. (1994) \\
\hline SPAR & Spartium witches' broom; Italy & 16S, SR & X92869 & Marcone et al. (1996) \\
\hline BAWB & Black alder witches' broom; Germany & $16 \mathrm{~S}$ & X76431 & Seemüller et al. (1994) \\
\hline PpYC & Papaya yellow crinkle; Queensland, Australia & $16 \mathrm{~S}, \mathrm{SR}$ & Y10097 & This paper \\
\hline PpM & Papaya mosaic; Queensland, Australia & $16 \mathrm{~S}, \mathrm{SR}$ & Y10096 & This paper \\
\hline TBB & Tomato big bud; South Australia, Australia & $16 \mathrm{~S}, \mathrm{SR}$ & Y08173 & Gibb et al. (1998) \\
\hline PnWB & Peanut witches' broom; Taiwan & $16 \mathrm{~S}$ & L33765 & Gundersen et al. (1994) \\
\hline SPWB & Sweet potato witches' broom; Taiwan & $16 \mathrm{~S}$ & L33770 & Gundersen et al. (1994) \\
\hline SUNHP & Sunn hemp witches' broom; Thailand & $16 \mathrm{~S}$ & $\mathrm{X} 76433$ & Seemüller et al. (1994) \\
\hline SPLL & Sweet potato little leaf; Northern Territory, Australia & $16 \mathrm{~S}, \mathrm{SR}$ & X90591 & Padovan et al. (1996) \\
\hline WBDL & Witches' broom disease of lime; Oman & $16 \mathrm{~S}, \mathrm{SR}$ & U15442 & Zreik et al. (1995) \\
\hline FBP & Faba bean phyllody; Sudan & $16 \mathrm{~S}, \mathrm{SR}$ & X83432 & Schneider et al. (1995a) \\
\hline wX & Western X-disease; CA, USA & $16 \mathrm{~S}$ & L04682 & Schneider et al. (1993) \\
\hline WX & Western X-disease; CA, USA & SR & U54992 & Smart et al. (1996) \\
\hline $\mathrm{CX}$ & Canadian peach X-disease; Ontario, Canada & $16 \mathrm{~S}$ & L33733 & Gundersen et al. (1994) \\
\hline VAC & Vaccinium witches' broom; Germany & $16 \mathrm{~S}$ & X76430 & Seemüller et al. (1994) \\
\hline TWB & Tsuwabuki witches' broom; Japan & $16 \mathrm{~S}$ & D12580 & Namba et al. (1993) \\
\hline CYE & Clover yellow edge; Ontario, Canada & $16 \mathrm{~S}$ & L33766 & Gundersen et al. (1994) \\
\hline $\mathrm{ICPh}$ & Clover phyllody; Italy & $16 S$ & X77482 & Firrao et al. (1996) \\
\hline SCWL & Sugar cane white leaf; Thailand & $16 \mathrm{~S}$ & $\mathrm{X} 76432$ & Seemüller et al. (1994) \\
\hline RYD & Rice yellow dwarf; Japan & $16 S$ & D12581 & Namba et al. (1993) \\
\hline BVK & $\begin{array}{l}\text { Blütenverkleinerung (from leafhopper Psammotettix } \\
\text { cephalotes); Germany }\end{array}$ & $16 \mathrm{~S}$ & X76429 & Seemüller et al. (1994) \\
\hline CIRP & From Cirsium arvense & $16 \mathrm{~S}, \mathrm{SR}$ & $\mathrm{X} 83438$ & $-\ddagger$ \\
\hline PPWB & Pigeon pea witches' broom; FL, USA & $16 \mathrm{~S}$ & L33735 & Gundersen et al. (1994) \\
\hline CPPWB & Caribbean pigeon pea witches' broom§ & $16 \mathrm{~S}$ & U18763 & $-\ddagger$ \\
\hline LY & Coconut lethal yellowing; FL, USA & $16 \mathrm{~S}$ & U18747 & $-\ddagger$ \\
\hline LDY & Yucatan coconut lethal decline; Mexico & $16 \mathrm{~S}$ & U18753 & $-\ddagger$ \\
\hline LD & Coconut lethal disease; Tanzania & $16 \mathrm{~S}$ & X80117 & $-\ddagger$ \\
\hline
\end{tabular}


Table 2. (cont.)

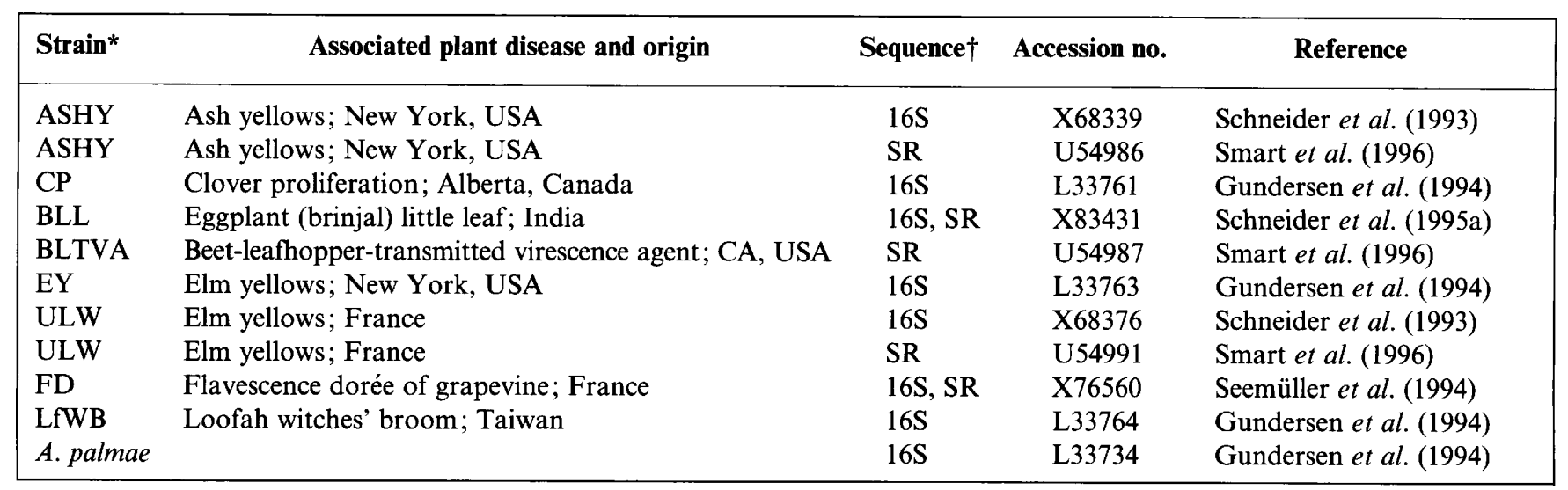

* Strains are presented in vertical order as they appear in Fig. 1, or for strains listed with only SR sequences, presented under phylogenetically similar strains.

$\uparrow$ 16S, 16S rRNA gene; SR, 16S-23S rRNA spacer region.

$\ddagger$ Database record was the only available reference at the time of analysis.

$\S$ Geographical origin could not be determined from database record.

The PpYC and PpM sequences were identical to each other.

\section{Phylogenetic analysis of 165 rDNA sequences}

A phylogenetic distance tree was calculated from a data set which excluded the strains OY, TWB and RYD (Fig. 1). This tree and that calculated from a data set which included strains OY, TWB and RYD both exhibited branching orders similar to previously published trees (Gundersen et al., 1994; Liefting et al., 1996; Marcone et al., 1996; Schneider et al., 1995a). High bootstrap values (Fig. 1) supported the same major phylogenetic clusters identified by Seemüller $e t$ al. (1994) and Schneider et al. (1995a), and the phylogenetic subclades identified by Gundersen $e t$ al. (1994) and R. E. Davis et al. (1997).

In this phylogenetic analysis (Fig. 1), PpDB was most closely related to the Australian grapevine yellows strain AGY and the New Zealand Phormium yellow leaf strain PYL phytoplasmas within subclade xii ( $R$. E. Davis et al., 1997), which corresponds to the stolbur sub-group of the aster yellows strain cluster, cluster I (Seemüller et al., 1994). Bootstrap values of $100 \%$ (Fig. 1) support the PpDB/AGY/PYL clade as being distinct from the STOL/VK clade. Direct pairwise comparison of the 16S rDNA sequences showed that the PpDB sequence was most similar to those of PYL $(99.9 \%)$, AGY $(99.7 \%)$, STOL $(98.3 \%)$ from Serbia and VK $(98.3 \%)$ from Germany. Similarity of the PpDB 16S rDNA sequence with those of the aster yellows strains ranged from $95.9 \%$ (AAY) to $97.3 \%$ (KV).

The PpYC and PpM phytoplasma 16S rDNA se- quences were identical to each other. In the phylogenetic analysis (Fig. 1), PpYC was most closely related to tomato big bud strain TBB from Australia, within the peanut witches' broom subclade (subclade iii) described by Gundersen et al. (1994), which corresponds to the faba bean phyllody strain cluster, cluster VI (Schneider et al., 1995a). PpYC, together with TBB, peanut witches' broom strain PnWB from Taiwan, sweet potato witches' broom strain SPWB from Taiwan, sunn hemp witches' broom strain SUNHP from Thailand and sweet potato little-leaf strain SPLL from Australia, form a clade (distance bootstrap value $97 \%$ ) distinct from lime witches' broom disease strain WBDL from Oman and faba bean phyllody strain FBP from Sudan (bootstrap value $100 \%$ ) (Fig. 1). Direct pairwise comparisons of sequences showed that the PpYC 16S rDNA sequence was most similar to those of TBB $(99.7 \%)$, PnWB (99.7\%), SUNHP (99.4\%), SPWB (99.1\%) and SPLL $(99 \cdot 1 \%)$. The PpYC sequence was $98.8 \%$ similar to the WBDL sequence and $98.6 \%$ similar to the FBP sequence, while only $92.3 \%$ similar to the sequence of strain WX in subclade iv. Direct sequence comparison also showed that the PpYC 16S rDNA sequence is 90.3\% similar to the PpDB sequence.

\section{S rRNA signature sequences}

R. E. Davis et al. (1997) described three 16S rRNA signature sequences that are unique to subclade xii phytoplasma strains and two signature sequences that were unique to the Australian grapevine yellows strain AUSGY. Although the available AUSGY 16S rRNA sequence is shorter than that of Australian grapevine yellows strain AGY (Padovan et al., 1996), the two 


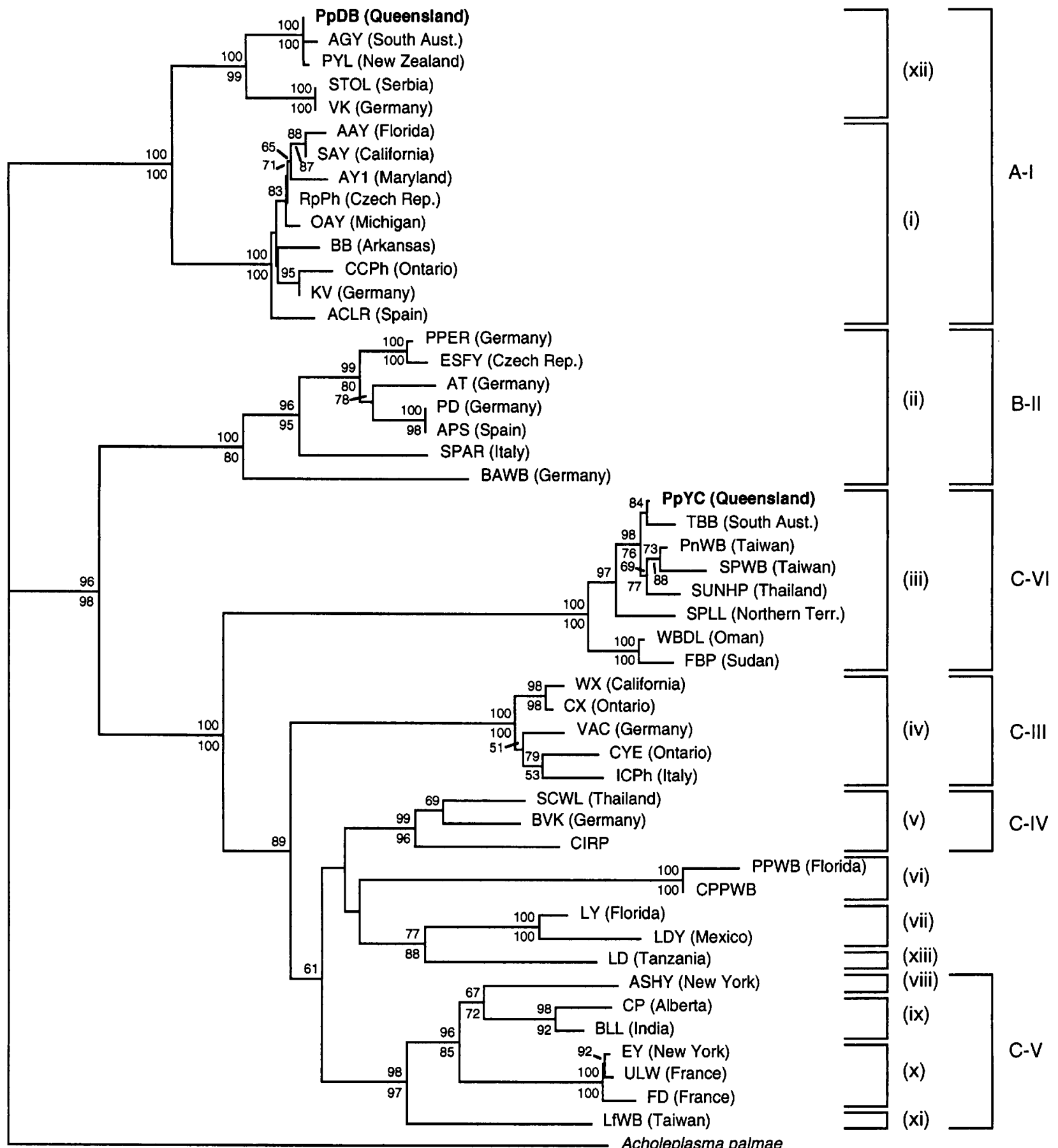

Fig. 1. Phylogenetic distance tree of $\mathrm{PpDB}, \mathrm{PpYC}$ and other phytoplasmas based on the comparative analysis of 1353 nucleotide positions of $16 \mathrm{~S}$ rRNA gene sequences, with two phylogenetic group classification systems presented [subclades of Gundersen et al. (1994), R. E. Davis et al. (1997) and this paper, and strain clusters of Seemüller et al. (1994) and Schneider et al. (1995a)]. Bar, phylogenetic distance of $10 \%$. Names of state or country of origin are in parentheses after strain name abbreviations (as presented in Table 2). Bootstrap values greater than $50 \%$ (100 bootstrap resamplings) from distance (upper) and parsimony (lower) analyses are presented at the nodes. Acholeplasma palmae was used as the outgroup in the analyses. 
sequences are identical within the matching regions. Since the AGY sequence is longer, it was used in the current phylogenetic analysis. The PpDB and PYL phytoplasma 16S rRNA sequences (this study; Liefting et al., 1996) have the same signature sequences described for AUSGY, thus distinguishing PpDB, PYL and AGY from STOL and VK, within subclade xii. Gundersen et al. (1994) reported two 16S rRNA signature sequences that are unique to subclade iii. These signature sequences occur only in PpYC, PpM and the other strains in subclade iii (Fig. 1). Additionally, the following two unique sequences that distinguish PpYC, PpM and TBB from other phytoplasma strains were found: 5'-TAAAAGGCATCTTTTATC-3' at positions 178-195 (numbering corresponding to $16 \mathrm{~S}$ rRNA gene sequence of OAY; Lim \& Sears, 1989) and 5'-CAAGGAAGAAAAGCAAATGGCGAACCATTTGTTT-3' at positions 444 477. PnWB, SPWB and SUNHP differ from the first unique sequence by having the same single nucleotide substitution, 5'-TAAAAGGCATCTTGTATC-3', and SPLL differs by an additional nucleotide substitution, 5'-TAGAAGGCATCTTGTATC-3'. SPLL contains the second unique oligonucleotide sequence exactly, whereas PnWB, SPWB and SUNHP differ by the same single nucleotide substitution, 5'CGAGG(25 nucleotides, see above)GTTT-3'.

\section{Analysis of 16S-23S spacer region DNA sequences}

All 25 phytoplasma sequences that were compared had tRNA $^{\text {Ile }}$ (GAT anticodon) genes $77 \mathrm{bp}$ in length. The tRNA $^{\text {Ile }}$ sequences of $\mathrm{PpDB}, \mathrm{PpYC}$ and $\mathrm{PpM}$ were identical to that of the OAY phytoplasma (Lim \& Sears, 1989). The similarity of sequences external to the tRNA ${ }^{\text {Ile }}$ gene in different phytoplasma strains reflected the same grouping observed in the phylogenetic tree based on the 16S rDNA sequence (data not shown). Direct pairwise comparisons of whole spacer region sequences showed PpDB to be most similar to PYL $(100 \%)$ and AGY (99.6\%), while showing only about $95 \%$ identity with subclade i strains SAY, RpPh and OAY. The 16S-23S spacer region DNA sequences of the PpYC and PpM phytoplasmas were identical to each other. PpYC and PpM are most similar to TBB $(99.6 \%)$ and SPLL $(99.6 \%)$, while showing $98.9 \%$ and $98.4 \%$ identity with WBDL and FBP, respectively, and only $83.0 \%$ identity with the subclade iv strain WX. The PpYC spacer region sequence is $87.8 \%$ similar to the $\mathrm{PpDB}$ sequence.

\section{DISCUSSION}

\section{Phytoplasma phylogenetic classification}

The phylogenetic tree presented in this paper (Fig. 1) is based on all near-complete phytoplasma 16S rDNA sequences that were available on public nucleic acid databases at the time of analysis. This represents an advance on earlier phylogenetic classifications, since previous studies (R. E. Davis et al., 1997; Liefting et al., 1996; Marcone et al., 1996; Padovan et al., 1996;
Schneider et al., 1995a; Zreik et al., 1995) included only representative strains from the subclades and strain clusters defined by Gundersen et al. (1994) and Seemüller et al. (1994). By including all available phytoplasma $16 \mathrm{~S}$ rDNA sequences in a single phylogenetic distance tree, the relationships of all strains to each other are clear, and the two current classification schemes can be directly compared (Fig. 1). Although the original phylogenetic trees published by Gundersen et al. (1994) and Seemüller et al. (1994) included only some strains from each of the distinct clades, the clustering of strains is sufficient to identify corresponding clades between the two systems.

Based on near-complete 16S rDNA sequences of 21 phytoplasma strains, Seemüller et al. (1994) originally identified the following five primary clusters: I, the aster yellows strain cluster; II, the apple proliferation strain cluster; III, the Western X-disease strain cluster; IV, the sugar cane white leaf strain cluster; and V, the elm yellows strain cluster. Schneider et al. (1995a) later distinguished the faba bean phyllody strain cluster, cluster VI, which includes strain SUNHP, previously included in cluster III (Seemüller et al., 1994). Based on near-complete 16S rDNA sequences of 19 phytoplasma strains, Gundersen et al. (1994) also recognized five major phylogenetic groups; however, two of these groups were different to those identified by Seemüller et al. (1994) due to the analysis of different phytoplasma strains. The five main groups distinguished by Gundersen et al. (1994) were further refined into the following 11 subclades by analysis of partial 16S rDNA sequences of 30 phytoplasma strains: $\mathrm{i}$, aster yellows strains; ii, apple proliferation strains; iii, peanut witches' broom strains; iv, X-disease strains; v, strain RYD; vi, strain PPWB; vii, strain LY; viii, strain ASHY; ix, clover proliferation strains; $x$, elm yellows strains; and xi, strain LfWB. R. E. Davis et al. (1997) later added strains STOL, VK and AUSGY, which formed a distinct subclade, designated subclade xii, most closely related to subclade $i$, the aster-yellowslike strains.

Liefting et al. (1996) included strains PYL, STOL and VK in a phylogenetic analysis and recognized that these three strains formed a subclade, which they named subclade xiii. However, R. E. Davis et al. (1997) defined this subclade as subclade xii, and this classification has been adopted in the current paper. Liefting et al. (1996) also included strains LY, LDY and LD. Although LD clustered with LY and LDY, it was separated from them by deep branches, such that LD could be assigned to its own subclade. Liefting et al. (1996) proposed the name subclade xii; however, 'subclade xiii' is more appropriate as the former designation conflicts with the naming of a different subclade by R. E. Davis et al. (1997) (Fig. 1). Also, Liefting et al. (1996) found that LY, LDY, LD and PPWB clustered together, and proposed naming this group as a seventh strain cluster in the classification system of Seemüller et al. (1994) and Schneider et al. (1995a). We agree that these strains, along with 
CPPWB, do cluster together (Fig. 1); however, nonsignificant bootstrap values (less than $95 \%$ ) do not support a distinct strain cluster. At present it would be best to recognize that these strains form three subclades, vi (PPWB and CPPWB), vii (LY and LDY) and xiii (LD), but should not be recognized as a distinct clade within the classification system of Seemüller $e t$ al. (1994) and Schneider et al. (1995a).

\section{PpDB and related strains}

PpDB is clearly related to the AGY and PYL phytoplasmas within subclade xii. Previously, restriction endonuclease analysis of the $\mathrm{P} 1 / \mathrm{P} 7$ amplimer from PpDB nucleic acid extracts revealed the similarities with AGY, STOLF (stolbur of tomato from France) and AAY (R. I. Davis et al., 1997; Gibb et al., 1996). Previous sequence analysis of a $500 \mathrm{bp}$ region of the 16S rRNA gene and the 16S-23S spacer region also revealed that the PpDB phytoplasma was closely related to STOL, VK and SAY (White et al., 1997). Restriction endonuclease analysis of the PCR-amplified tuf gene further supported the close genetic relationship between the PpDB and AGY phytoplasmas (Padovan et al., 1996). These studies also indicated that the PpDB/AGY strains are distinct from the STOL/VK strains. The results of $16 \mathrm{~S}$ rDNA and $16 \mathrm{~S}-23 \mathrm{~S}$ spacer region DNA sequence analyses presented in this paper confirm the close genetic relatedness of $\mathrm{PpDB}$ to AGY, and clearly demonstrate the close relationship of these phytoplasma strains to the PYL phytoplasma from New Zealand. Within subclade xii, PpDB, AGY and PYL form a clade distinct from the European strains STOL and VK (Fig. 1). Based on the 16S rDNA sequence data, PpDB and PYL can also be included in the 16S rDNA RFLP subgroup 16SrI-J, with AUSGY and AGY (R. E. Davis et al., 1997).

\section{PpYC, PpM and related strains}

Previous restriction endonuclease analysis (Gibb et al., 1996) and sequence analysis (White et al., 1997) of amplified 16S rDNA and 16S-23S spacer region DNA revealed identity between those regions of DNA of the PpYC and PpM phytoplasmas. Gibb et al. (1996) and White et al. (1997) speculated that the same strain, or very similar strains of phytoplasmas, were responsible for papaya yellow crinkle and mosaic, and that the differences in disease symptoms may be due to differences in plant physiological and or pathological factors. Investigation of other genomic sequences may reveal differences between PpYC and PpM. The PpYC and $\mathrm{PpM}$ phytoplasmas were previously found to be similar to TBB and SPLL from Australia, and SUNHP, SEPT (sesame phyllody), CLP (Cleome viscosa phyllody) and CROP (crotalaria phyllody) from Thailand, by RFLP analysis of P1/P7 amplimers (R. I. Davis et al., 1997; Gibb et al., 1996), and similar to PnWB, SUNHP and WBDL by sequence analysis (White et al., 1997). Greber (1966) had previously demonstrated the close relationship between the papaya yellow crinkle and tomato big bud agents by dodder transmission experiments.

The results presented in this paper confirm that the $\mathrm{PpYC}$ and PpM phytoplasmas are most closely related to the Australian TBB and SPLL phytoplasmas, as well as the South-East Asian SUNHP, PnWB and SPWB phytoplasmas, which belong to subclade iii (Gundersen et al., 1994) or strain cluster VI (Schneider et al., 1995a). Within this clade are the FBP and WBDL phytoplasmas from Sudan and Oman, respectively. Previously, strains FBP and WBDL were each grouped only with SUNHP in separate publications (Schneider et al., 1995a; Zreik et al., 1995). The phylogenetic tree presented in Fig. 1, along with pairwise comparisons of the $16 \mathrm{~S}$ and $16 \mathrm{~S}-23 \mathrm{~S}$ spacer region sequences $(99.5 \%$ identity in $16 \mathrm{~S}$ rDNA sequence and $99.6 \%$ identity in the $16 \mathrm{~S}-23 \mathrm{~S}$ spacer region sequence), clearly show that strains FBP and WBDL are more closely related to each other than to the other subclade iii strains.

\section{Origins of Australian phytoplasma strains}

In a survey of Australian phytoplasma diseases, R. I. Davis et al. (1997) found that the majority of diseases occurring in the 38 plant species tested were associated with the TBB strain. The closely related SPLL strain occurred only in sweet potato (Ipomoea batatas) and pigeon pea (Cajanus cajan). The only other strain detected was the AGY/PpDB strain. Due to the ubiquity of the TBB strain and the close relationship of TBB and SPLL strains to other phytoplasma strains (subclade iii strains) occurring only in Southern Asia, R. I. Davis et al. (1997) hypothesized an Australasian origin of TBB and SPLL strains. WBDL and the strains represented by FBP (Schneider et al., 1995a) form a distinct clade within subclade iii, and have a recorded geographical distribution extending from Thailand in South-East Asia to Sudan in North-East Africa. Based on this distinct geographical distribution, it seems very likely that the subclade iii phytoplasmas originated and evolved in Southern Asia, with an apparent evolutionary and geographical divergence to form the South-West Asian strains (FBP and WBDL) and the South-East Asian/Australasian strains.

The AGY-like strains have only been detected in grapevines (Vitis vinifera) and papaya in Australia and New Zealand flax (Phormium tenax). The next most closely related strains, the STOL-like strains, have only been found in Europe. Currently, there is no explanation for the apparent close relatedness yet distinct geographical separation of the AGY- and STOL-like strains. Although, at present, it seems that the AGY-like strains are endemic to Australia and New Zealand, their actual origin and evolutionary relationship with the STOL-like strains can only be speculated until they are detected in more plant host and/or insect vector species. 


\section{Phytoplasma taxa}

Since the proposal to use the name 'phytoplasma' for the plant-pathogenic mycoplasma-like organisms (Tully, 1993; Sears \& Kirkpatrick, 1994), there has been increasing support for recognizing the phytoplasmas as a distinct genus (R. E. Davis et al., 1997; Gundersen et al., 1994; Zreik et al., 1995). Also, Gundersen et al. (1994) proposed that each phylogenetically distinct subclade should represent at least distinct species.

R. E. Davis et al. (1997) defined the provisional taxon 'Candidatus Phytoplasma australiense' based on $16 \mathrm{~S}$ rRNA signature sequences of AUSGY, which have since been found in strains PpDB, AGY and PYL, thus supporting a distinct group of closely related strains. Due to their close genetic relationship and distinct geographical range, we propose that strains PpDB, AGY and PYL be provisionally included in the taxon 'Candidatus Phytoplasma australiense'.

Zreik et al. (1995) proposed the taxon 'Candidatus Phytoplasma aurantifolia' based on the WBDL strain $16 \mathrm{~S}$ rDNA sequence. Phylogenetic analysis and direct pairwise sequence comparison in the present study have shown that strain FBP and strain WBDL are more closely related to each other than to any other characterized strains. The 16S rRNA gene oligonucleotide sequence listed by Zreik et al. (1995) to define strain WBDL as 'Candidatus Phytoplasma aurantifolia' differs from the corresponding sequence of other subclade iii phytoplasma strains by two nucleotide substitutions and differs from that of FBP by a single nucleotide substitution. Despite this single nucleotide difference in the definitive oligonucleotide, the current phylogenetic study statistically supports $(100 \%$ bootstrap; Fig. 1) the inclusion of FBP and WBDL in a taxon distinct from the other subclade iii strains. Thus we suggest that strain FBP is sufficiently similar to WBDL to provisionally be included in the taxon 'Candidatus Phytoplasma aurantifolia'.

Based on the guidelines of Murray \& Schleifer (1994), we propose that the PpYC, PpM and TBB phytoplasmas be assigned to a new Candidatus species with the following description: 'Candidatus Phytoplasma australasia' [(Mollicutes) NC; NA; O; NAS (EMBL $Y 10097$ ), oligonucleotide sequences of unique regions of the 16S rRNA gene 5'-TAAAAGGCATCTTTTATC-3' and 5'-CAAGGAAGAAAAGCAAATGGCGAACCATTTGTTT-3'; P (Carica papaya, Lycopersicon esculentum, phloem); M]. Although strains PnWB, SPWB, SUNHP and SPLL from subclade iii have minor variations in sequence regions that are unique to strains in 'Candidatus Phytoplasma australasia' (PpYC, PpM and TBB), we suggest that they be provisionally included in this taxon because of the close phylogenetic relationships of all these strains (Fig. 1) and their distinct geographic range from South-East Asia to Australia.

As an economically important group of mollicutes, we support efforts to 'facilitate reference to (each) unique phytoplasma lineage' (R. E. Davis et al., 1997) by describing putative taxa, despite the inability to culture these organisms. Future taxonomic definitions which are based primarily on nucleic acid sequence information should be based on more than one conserved gene. Sequence analysis of conserved phytoplasma genes, in addition to the $16 \mathrm{~S}$ rRNA gene, is likely to reveal more clearly the relationships between those strains which we have suggested be provisionally placed in the three discussed Candidatus species. Geographic and host range should also be considered as important criteria. Fortunately, due to their obligate parasitic nature, it is likely that phytoplasma genetic diversity will reflect the biogeography of their hosts. Finally, for practical reasons, the taxonomic system may be weighted with taxa for which there is a need to refer to as distinct pathogens of cultivated plants. For example, two geographically isolated strains of economic importance, with greater than $99 \%$ sequence similarity or significant phylogenetic confidence (bootstrap) values, may be distinguished as separate species, while two co-located strains or non-economic strains may remain grouped within a single species.

\section{ACKNOWLEDGEMENTS}

We thank Jodie Guthrie for technical guidance during DNA sequencing. This research was supported by grants from the Queensland Fruit and Vegetable Growers, Horticultural Research and Development Corporation (FR9617), Australian Research Council (Small Grant) and the Central Queensland University Research Grant scheme. D.T.W. is the recipient of an Australian Postgraduate Research Award.

\section{REFERENCES}

Altschul, S. F., Gish, W., Miller, W., Myers, E. W. \& Lipman, D. J. (1990). Basic local alignment search tool. J Mol Biol 215, 403-410.

Blackall, L. L., Seviour, E. M., Cunningham, M. A., Seviour, R. J. \& Hugenholtz, P. (1994). "Microthrix parvicella" is a novel, deep branching member of the actinomycetes subphylum. Syst Appl Microbiol 17, 513-518.

Bowyer, J. W., Atherton, J. G., Teakle, D. S. \& Ahern, G. A. (1969). Mycoplasma-like bodies in plants affected by legume little leaf, tomato big bud, and lucerne witches' broom diseases. Aust $J$ Biol Sci 22, 271-274.

Bradford, D., Hugenholtz, P., Seviour, E. M., Cunningham, M. A., Stratton, H., Seviour, R. J. \& Blackall, L. L. (1996). 16S rRNA analysis of isolates obtained from gram-negative, filamentous bacteria micromanipulated from activated sludge. Syst Appl Microbiol 19, 334-343.

Condé, B., Ulyatt, L. \& Pitkethley, R. (1996). Occurrences of Australian papaya dieback, yellow crinkle and other diseases or disorders of papaya with similar symptoms recorded from the Northern Territory of Australia. Pac Assoc Trop Phytopathol Newsl 14, 2-6.

Davis, M. J., Kramer, J. B., Ferwerda, F. H. \& Brunner, B. R. (1996). Association of a bacterium and not a phytoplasma with papaya bunchy top disease. Phytopathology 86, 102-109. 
Davis, R. E., Dally, E. L., Gundersen, D. E., Lee, I.-M. \& Habili, N. (1997). "Candidatus Phytoplasma australiense," a new phytoplasma taxon associated with Australian grapevine yellows. Int J Syst Bacteriol 47, 262-269.

Davis, R. I., Schneider, B. \& Gibb, K. S. (1997). Detection and differentiation of phytoplasmas in Australia. Aust $J$ Agric Res 48, 535-544.

Deng, S. \& Hiruki, C. (1991). Amplification of 16S rRNA genes from culturable and non-culturable Mollicutes. $J$ Microbiol Methods 14, 53-61.

Dorsch, M. \& Stackebrandt, E. (1992). Some modifications in the procedure of direct sequencing of PCR amplified 16S rDNA. $J$ Microbiol Methods 16, 271-279.

Felsenstein, J. (1985). Confidence limits on phylogenies: an approach using the bootstrap. Evolution 39, 783-791.

Felsenstein, J. (1993). PHYLIP - Phylogeny Inference Package (version 3.5).

Firrao, G., Carrao, L., Gobbi, E. \& Locci, R. (1996). Molecular characterization of a phytoplasma causing phyllody in clover and other herbaceous hosts in Northern Italy. Eur $J$ Plant Pathol 102, 817-822.

Gibb, K. S., Persley, D. M., Schneider, B. \& Thomas, J. E. (1996). Phytoplasmas associated with papaya diseases in Australia. Plant Dis 80, 174-178.

Gibb, K. S., Schneider, B. \& Padovan, A. C. (1998). Differential detection and genetic relatedness of phytoplasma in papaya. Plant Pathol 47, 325-332.

Glennie, J. D. \& Chapman, K. R. (1976). A review of dieback - a disorder of the papaw (Carica papaya L.) in Queensland. Qld $J$ Agric Anim Sci 33, 177-188.

Gowanlock, D. H., Greber, R. S., Behncken, G. M. \& Finlay, J. (1976). Electron microscopy of mycoplasma-like bodies in several Queensland crop species. Aust Plant Pathol Soc Newsl 5 (suppl.), abstract 223.

Greber, R. S. (1966). Identification of the virus causing papaw yellow crinkle with tomato big bud virus by transmission tests. Qld J Agric Anim Sci 23, 147-153.

Gundersen, D. E., Lee, I.-M., Rehner, S. A., Davis, R. E. \& Kingsbury, D. T. (1994). Phylogeny of mycoplasmalike organisms (phytoplasmas): a basis for their classification. $J$ Bacteriol 176, 5244-5254.

Gundersen, D. E., Lee, I.-M., Schaff, D. A., Harrison, N. A., Chang, C. J., Davis, R. E. \& Kingsbury, D. T. (1996). Genomic diversity and differentiation among phytoplasma strains in 16S rRNA groups I (aster yellows and related phytoplasmas) and III (Xdisease and related phytoplasmas). Int J Syst Bacteriol 46, 64-75.

Kuske, C. R. \& Kirkpatrick, B. C. (1992). Phylogenetic relationships between the western aster yellows mycoplasmalike organism and other prokaryotes established by 16S rRNA gene sequence. Int J Syst Bacteriol 42, 226-233.

Lane, D. J. (1991). 16S/23S rRNA sequencing. In Nucleic Acid Techniques in Bacterial Systematics, pp. 115-175. Edited by E. Stackebrandt \& M. Goodfellow. Chichester: Wiley.

Larsen, N., Olsen, G. J., Maidak, B. L., McCaughey, M. J., Overbeek, R., Macke, T. J., Marsh, T. L. \& Woese, C. R. (1993). The ribosomal database project. Nucleic Acids Res 21, 3021-3023.

Lee, I.-M. \& Davis, R. E. (1992). Mycoplasmas which infect plants and insects. In Mycoplasmas: Molecular Biology and Pathogenesis, pp. 379-390. Edited by J. Maniloff, R. N. McElhaney, L. R. Finch \& J. B. Baseman. Washington, DC: American Society for Microbiology.
Lee, I.-M., Hammond, R. W., Davis, R. E. \& Gundersen, D. E. (1993). Universal amplification and analysis of pathogen $16 \mathrm{~S}$ rDNA for classification and identification of mycoplasmalike organisms. Phytopathology 83, 834-842.

Liefting, L. W., Andersen, M. T., Beever, R. E., Gardner, R. C. \& Forster, R. L. S. (1996). Sequence heterogeneity in the two $16 \mathrm{~S}$ rRNA genes of Phormium yellow leaf phytoplasma. Appl Environ Microbiol 62, 3133-3139.

Lim, P.-O. \& Sears, B. B. (1989). 16S rRNA sequence indicates that plant-pathogenic mycoplasmalike organisms are evolutionarily distinct from animal mycoplasmas. $J$ Bacteriol 171, 5901-5906.

Liu, B., White, D. T., Walsh, K. B. \& Scott, P. T. (1996). Detection of phytoplasmas in dieback, yellow crinkle, and mosaic diseases of papaya using polymerase chain reaction techniques. Aust $J$ Agric Res 47, 387-394.

McCoy, R. E., Caudwell, A., Chang, C. J. \& 15 other authors (1989). Plant diseases associated with mycoplasma-like organisms. In The Mycoplasmas, vol. 5, pp. 545-640. Edited by R. F. Whitcomb \& J. G. Tully. New York: Academic Press.

Marcone, C., Ragozzino, A., Schneider, B., Lauer, U., Smart, C. D. \& Seemuller, E. (1996). Genetic characterization and classification of two phytoplasmas associated with spartium witches'broom disease. Plant Dis 80, 365-371.

Murray, R. G. E. \& Schleifer, K. H. (1994). Taxonomic notes: a proposal for recording the properties of putative taxa of procaryotes. Int J Syst Bacteriol 44, 174-176.

Namba, S., Oyaizu, H., Kato, S., Iwanami, S. \& Tsuchizaki, T. (1993). Phylogenetic diversity of phytopathogenic mycoplasmalike organisms. Int J Syst Bacteriol 43, 461-467.

Padovan, A. C., Gibb, K. S., Daire, X. \& Boudon-Padieu, E. (1996). A comparison of the phytoplasma associated with Australian grapevine yellows to other phytoplasmas in grapevine. Vitis $\mathbf{3 5}$, 189-194.

Peterson, R. A., Coates, L. M. \& Persley, D. M. (1993). Diseases of papaw (papaya). In Diseases of Fruit Crops, pp. 70-76. Edited by D. M. Persley. Brisbane: Queensland Department of Primary Industries.

Schneider, B., Ahrens, U., Kirkpatrick, B. C. \& Seemüller, E. (1993). Classification of plant-pathogenic mycoplasma-like organisms using restriction-site analysis of PCR-amplified 16S rDNA. $J$ Gen Microbiol 139, 519-527.

Schneider, B., Cousin, M. T., Klinkong, S. \& Seemüller, E. (1995a). Taxonomic relatedness and phylogenetic positions of phytoplasmas associated with diseases of faba bean, sunnhemp, sesame, soybean, and eggplant. J Plant Dis Prot 102, 225-232. Schneider, B., Seemuller, E., Smart, C. D. \& Kirkpatrick, B. C. (1995b). Phylogenetic classification of plant pathogenic mycoplasma-like organisms or phytoplasmas. In Molecular and Diagnostic Procedures in Mycoplasmology, vol. 1, pp. 369-380. Edited by S. Razin \& J. G. Tully. San Diego: Academic Press.

Sears, B. B. \& Kirkpatrick, B. C. (1994). Unveiling the evolutionary relationships of plant-pathogenic mycoplasmalike organisms. ASM News 60, 307-312.

Seemúller, E., Schneider, B., Mäurer, R. \& 8 other authors (1994). Phylogenetic classification of phytopathogenic mollicutes by sequence analysis of $16 \mathrm{~S}$ ribosomal DNA. Int J Syst Bacteriol 44, 440-446.

Simmonds, J. H. (1965). Papaw diseases. Qld Agric J 91, 666-677. Smart, C. D., Schneider, B., Blomquist, C. L., Guerra, L. J., Harrison, N. A., Ahrens, U., Lorenz, K.-H., Seemüller, E. \& Kirkpatrick, B. C. (1996). Phytoplasma-specific PCR primers based on sequences 
of the 16S-23S rRNA spacer region. Appl Environ Microbiol 62 , 2988-2993.

Stackebrandt, E. \& Charfreitag, O. (1990). Partial 16S rRNA primary structure of five Actinomyces species: phylogenetic implications and development of an Actinomyces israeliispecific oligonucleotide probe. J Gen Microbiol 136, 37-43.

Thompson, J. D., Higgins, D. G. \& Gibson, T. J. (1994). CLUSTAL W: improving the sensitivity of progressive multiple sequence alignment through sequence weighting, position specific gap penalties and weight matrix choice. Nucleic Acids Res 22, 4673-4680.

Tully, J. G. (1993). International Committee on Systematic Bac- teriology Subcommittee on the Taxonomy of Mollicutes. Minutes of the Interim Meetings, 1 and 2 August 1992, Ames, IA, USA. Int J Syst Bacteriol 43, 394-397.

White, D. T., Billington, S. J., Walsh, K. B. \& Scott, P. T. (1997). DNA sequence analysis supports the association of phytoplasmas with papaya (Carica papaya) dieback, yellow crinkle and mosaic. Australas Plant Pathol 26, 28-36.

Zreik, L., Carle, P., Bové, J. M. \& Garnier, M. (1995). Characterization of the mycoplasmalike organism associated with witches'-broom disease of lime and proposition of a Candidatus taxon for the organism, "Candidatus Phytoplasma aurantifolia”. Int J Syst Bacteriol 45, 449-453. 